\title{
Evaluation of Stress Corrosion Cracking Damage to an API 5L X52 Pipeline Transporting Ammonia: A Case Study
}

\author{
José Luis Mora-Mendoza', Mónica Jazmín Hernández-Gayosso², Daniel Antonio Morales-Serrat ${ }^{1}$, \\ Octaviano Roque-Oms¹, Digna Alejandra Del Angel'1, Gerardo Zavala-Olivares ${ }^{2}$ \\ ${ }^{1}$ Petróleos Mexicanos, Marina Nacional 329, Col. Petróleos Mexicanos, CDMX, Ciudad de México, México \\ ${ }^{2}$ Instituto Mexicano del Petróleo, Eje Central Lázaro Cárdenas Norte 152, Col. San Bartolo Atepehuacan, CDMX, Ciudad de México, \\ México \\ Email: gzavala@imp.mx
}

How to cite this paper: Mora-Mendoza, J.L., Hernández-Gayosso, M.J., MoralesSerrat, D.A., Roque-Oms, O., Del Angel, D.A. and Zavala-Olivares, G. (2016) Evaluation of Stress Corrosion Cracking Damage to an API 5L X52 Pipeline Transporting Ammonia: A Case Study. Materials Sciences and Applications, 7, 610-622.

http://dx.doi.org/10.4236/msa.2016.710050

Received: September 10, 2016

Accepted: October 9, 2016

Published: October 12, 2016

Copyright $\odot 2016$ by authors and Scientific Research Publishing Inc. This work is licensed under the Creative Commons Attribution International License (CC BY 4.0).

http://creativecommons.org/licenses/by/4.0/

\section{Abstract}

The high number of leak events that took place in recent years at a $25.4 \mathrm{~cm}(10$ ") $\varnothing$ pipeline transporting anhydrous liquid ammonia, located in the Southeast of Mexico, was the main reason to carry out a number of field studies and laboratory tests that helped establish not only the failure causes but also mitigation and control solutions. The performed activities included direct evaluation at failure sites, total repair programs, metallographic studies and pipeline flexibility analyses. The obtained results were useful to conclude that the failures obeyed a cracking mechanism by Stress Corrosion Cracking (SCC) which was caused by the combined effect of different factors: high stress resistance, high hardness of the base metal with a microstructure prone to brittleness and residual strains originated during the pipeline construction. From the operative, logistic and financial standpoints, it is not feasible to release the stress of approximately $22 \mathrm{~km}$ of pipeline. Therefore, the only viable solution is to install a new pipeline with suitable fabrication, construction and installation specifications aimed at preventing the SCC phenomenon.

\section{Keywords}

Stress Corrosion Cracking, Residual Stress, Ammonia Transporting Pipeline

\section{Introduction}

It is well known that the Stress Corrosion Cracking (SCC) mechanism is caused by the combination of tensile stress and a corrosive medium [1]. Generally, SCC provokes cracks and fractures with a sudden structure rupture [2]-[4]. 
Tensile stress can stem from either stress applied directly on a structure or residual stress originated during the production and/or construction processes. Examples of processes that trigger residual stress are cold working processes [5], welding, thermal treatments and machining.

In general, during the SSC mechanism, most part of the structure surface is not attacked by corrosion and frequently, thin cracks appear penetrating the material through intergranular or transgranular forms [6]. Macroscopically speaking, the SSC fractures feature a fragile appearance [7]-[8].

SCC has been classified as a catastrophic type of corrosion, where it is difficult to detect fine cracks and the damage is not easily predictable. A disastrous failure can occur all of a sudden with a minimum loss of total material [9].

In the past, SSC was considered as a problem coming from some alloys in specific environments. However, currently, it is known that SCC has occurred in a wide variety of alloy systems in different environments [10]-[12].

Low alloy steel types are less susceptible to SCC than high alloy steels, although these materials are exposed to SCC in water containing chloride ions [2]. Likewise, low hardness steels provide apparently a higher resistance degree to SCC than high resistance steels [13].

The most effective ways to prevent SCC from happening are: the use of suitable materials, reduction or elimination of stress sources and removal of critical species from the medium. Some SCC control methods include the stress relief by means of a thermal treatment after the welding process, protecting coatings and corrosion inhibitors, among others [3] [14].

On the other hand, several important events have been reported at pipelines transporting anhydrous liquid ammonia [15]. Most of these events occurred in the USA, which is a country where the highest number of pipelines transporting anhydrous liquid ammonia is located. In nine important events, it was reported that the causes had been: overpressure (1), external corrosion (2), maintenance problems (1), fatigue cracking (1), weld failure (1), unexpected failure during the freezing-melting cycle (1) and vandalism (2).

Likewise, it is known [13] that liquid ammonia can cause SCC in carbon steels in the presence of oxygen, although it has been established that high stress levels are required to start the cracking process. The residual strains in welds of materials with high and intermediate hardness or welds with high hardness accompanied by residual strains can be enough to trigger SCC when oxygen is present at the right concentration for this process to take place.

In this work, a case study originated by the high frequency of leak events taking place at a $25.4 \mathrm{~cm}$ (10") Ø pipeline transporting anhydrous liquid ammonia is presented.

Several field and laboratory analyses were carried out in order to establish the causes for the leaks in the pipeline. The SCC is considered as the main metal failure process. The sources for this kind of mechanism were determined and the applicable solutions for the problem were given. 


\section{Background}

The studied pipeline is made from API 5L X52 steel with no longitudinal seam; it has an approximate length of $46 \mathrm{Km}$, with diameter of $25.4 \mathrm{~cm}$ (10 inches) and a nominal wall thickness of $0.9271 \mathrm{~cm}(0.365$ inches $)$. The pipeline transports anhydrous liquid ammonia at an operation pressure of $28 \mathrm{~kg} \cdot \mathrm{cm}^{-2}$ and an output temperature between -5 and $0^{\circ} \mathrm{C}$. The maximum historical operation pressure at the pipeline has been 40 $\mathrm{kg} \cdot \mathrm{cm}^{-2}$.

The statistics of events at the pipeline reports 20 leaks for a period of 13 operation years, from which 17 occurred in three consecutive years, as shown in Table 1.

In most failure points, circumferential fractures were identified which were close to the field welds, and generally located at 12 technical hours from the pipeline (Figure 1). In general, these types of circumferential fractures tend to be favored in their formation and propagation by axial stress and pipeline flexion. In five leaks, it was not possible to identify the type of damage caused to the pipeline, due to the priority assigned to repair and eliminate the leak to reestablish the product transportation.

Table 1. Statistics of ammonia leaks.

\begin{tabular}{cc}
\hline Years of operation of the pipeline transport system & Ammonia leaks \\
\hline 2 & 2 \\
7 & 1 \\
11 & 5 \\
12 & 6 \\
13 & 6 \\
Total & 20 \\
\hline
\end{tabular}

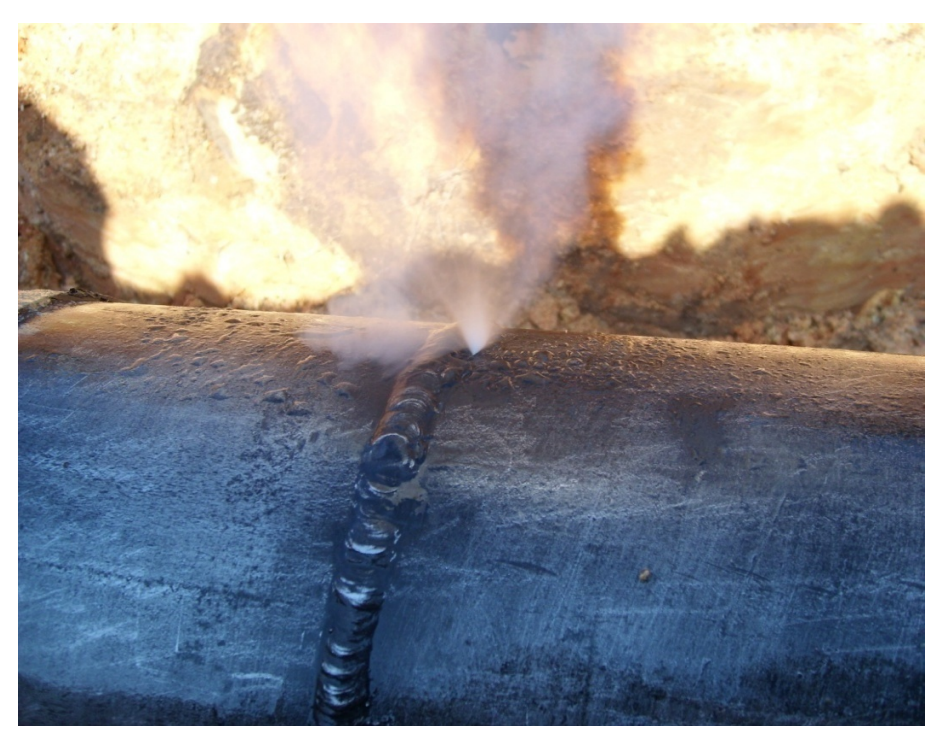

Figure 1. Ammonia leak located close to a circumferential weld, at 12 technical hours from the pipeline. 


\section{Initial Field and Laboratory Studies}

After two years of its construction, a number of field and laboratory activities were carried out to establish the failure causes of the two first leaks that occurred at the pipeline, reporting the following findings:

1) During the direct evaluation at 17 sites, there were pipeline segments with displacements between the original plane and the cut section, of more than $90 \mathrm{~cm}$, which recovered their linearity after removing them from the ditches (Figure 2).

2) The laboratory results reported cracks in the analyzed segments, which were associated to the stress corrosion cracking (SCC) mechanism. The origin of the strains was attributed to the inadequate field conformation of the pipeline by forcing the pipes to adjust to the terrain topographic profile.

\subsection{Metallographic Analyses}

Because of the high occurrence of leaks at the pipeline after 12 and 13 operation years, metallographic analyses were carried out [16]-[19]. It was established that the stress resistance of the base metal was considerably higher than the one specified for API $5 \mathrm{~L}$ X52 steel [20] (Table 2). The base metal showed high hardness, which is characteristic of a brittle microstructure [21] [22] (Table 3).

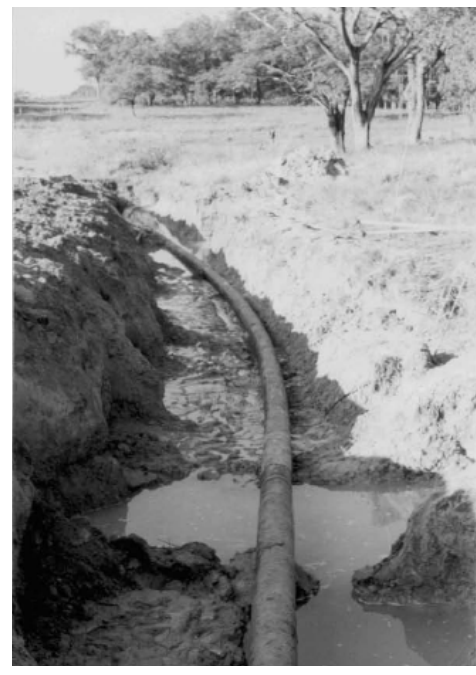

(a)

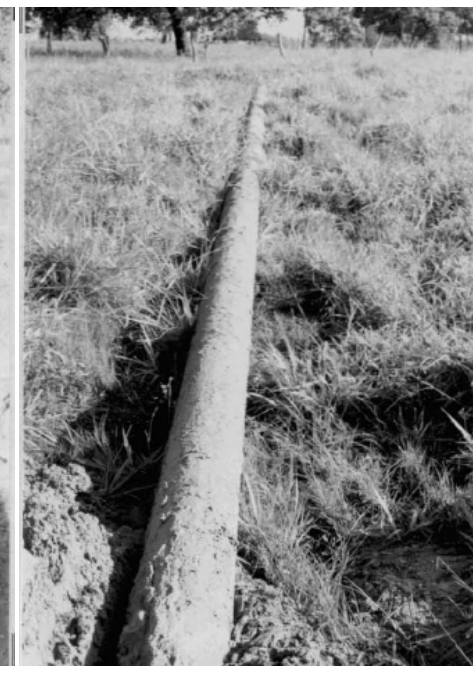

(b)

Figure 2. (a) Curved pipeline; (b) Withdrawn section with linearity recovery.

Table 2. Yield and tensile strengths [20].

\begin{tabular}{|c|c|c|}
\hline Sample or specification & Yield strength $\mathrm{Kg} \cdot \mathrm{cm}^{-2}$ (PSI) & Tensile strength $\mathrm{Kg} \cdot \mathrm{cm}^{-2}$ (PSI) \\
\hline A & 4935 (70,500 PSI) & $6874(98,200$ PSI $)$ \\
\hline API 5L X65 & 4550 (minimum) (65,000 PSI) & 5390 (minimum) (77,000 PSI) \\
\hline API 5L X70 & 4900 (minimum) (70,000 PSI) & 5740 (minimum) (82,000 PSI) \\
\hline
\end{tabular}


The microstructure of the base metal showed abnormal carbon segregation and pearlite acicular morphology, characteristic of a fragile microstructure [16] (Figure 3). The presence of fractures with fragile aspect and multiple cracking was also identified. Neither metal loss nor pitting corrosion occurred (Figure 4). The cracks, being of the transgranular type, displayed trajectories going from the interior to the exterior part of the pipeline wall (Figure 5).

Based on the results of these metallographic analyses, it was concluded that the failures obeyed to a stress corrosion cracking (SCC) mechanism, which was originated by various factors: high stress resistance, high hardness, a brittleness-susceptible microstructure and the presence of residual stress that was probably originated from the pipeline construction and lying.

Here, the three conditions required for the occurrence of SCC were achieved:

- A susceptible material.

- An environment that causes SCC for that material.

- Sufficient tensile stress to induce SCC.

This situation was observed by means of the analyses performed to the base metal,

Table 3. Brinell hardness.

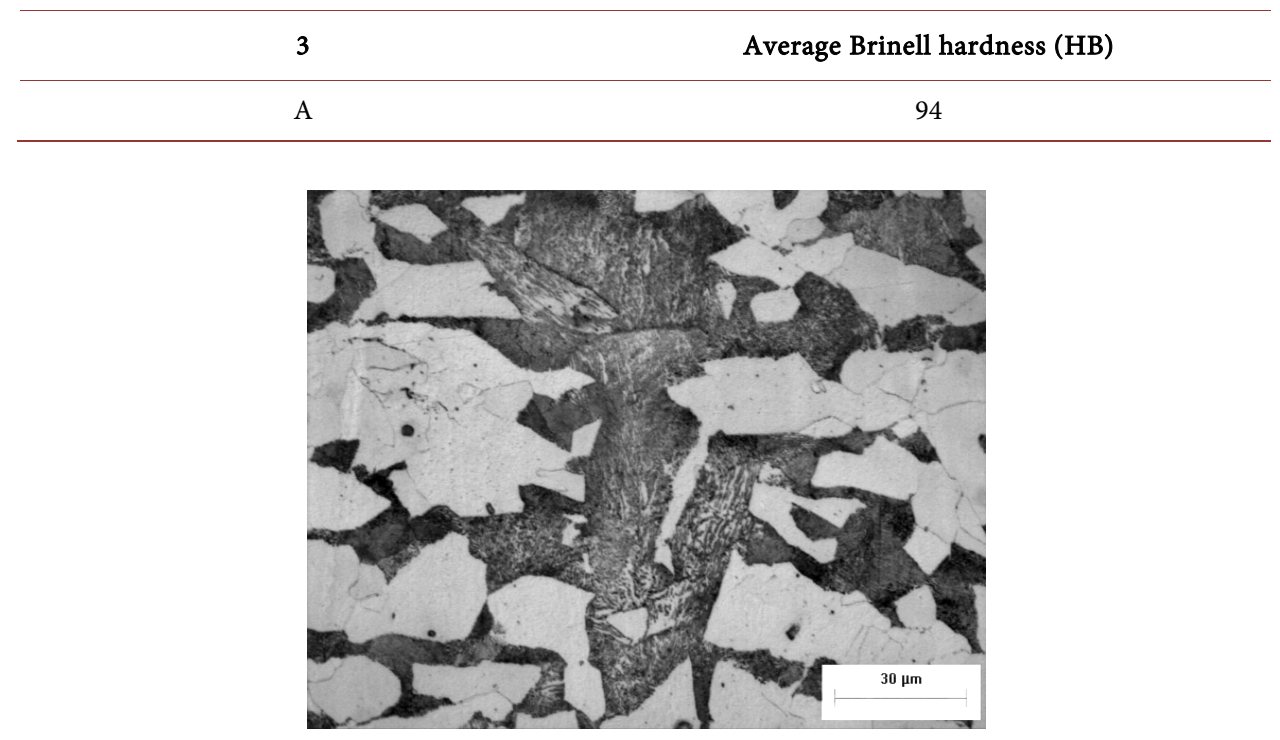

Figure 3. Base metal microstructure.

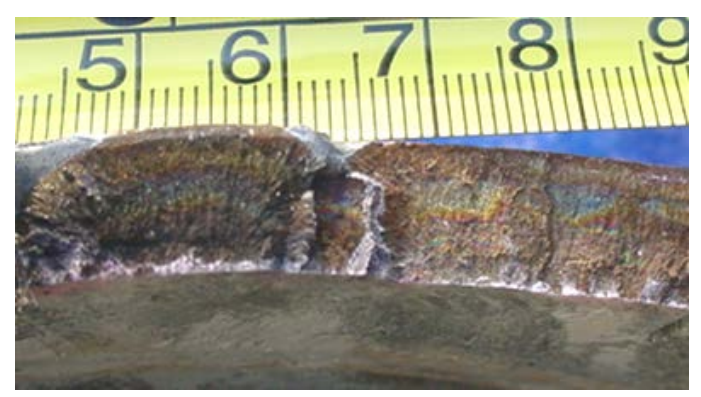

Figure 4. Brittle fracture. 
where it was possible to observe the changes originated during the tube construction and the strains caused by the criterion considered for the pipeline lying.

\subsection{Total Repair Actions}

Due to the constant failures that occurred between the 12th and 13th years of service, the "split sleeve" repairs used to stop the leaks, were replaced by new pipelines sections (reels). During these works, the presence of residual stress induced during the pipeline construction was confirmed. The most remarkable results of these works were:

1) At the $3+300$ kilometer, once the pipeline cut was finished, a linear displacement of approximately $4 \mathrm{~cm}$ was observed (Figure 6), which made necessary further digging, in order to match correctly the pipe and release the present stress.

2) At the $8+025$ kilometer, the pipeline cut was finished and a linear displacement of approximately $5 \mathrm{~cm}$ was also observed, as shown in Figure 7. It was necessary to continue digging to match correctly the pipe and release the present stress.

3) At the $15+137$ kilometer, which is close to a sectional valve, a pipe vertical displacement of approximately $4 \mathrm{~cm}$ was observed when the valve flange was unscrewed, Figure 8. In order to perform the total repair, it was necessary to modify the valve supports to match the flanges and release the present stress.
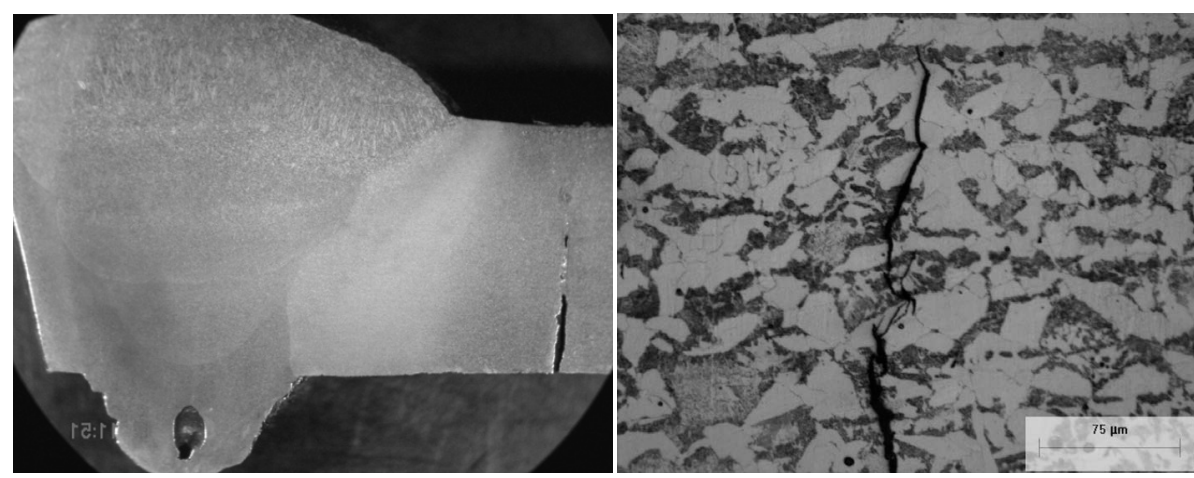

Figure 5. Microscopy fractography analysis and transgranular cracks.
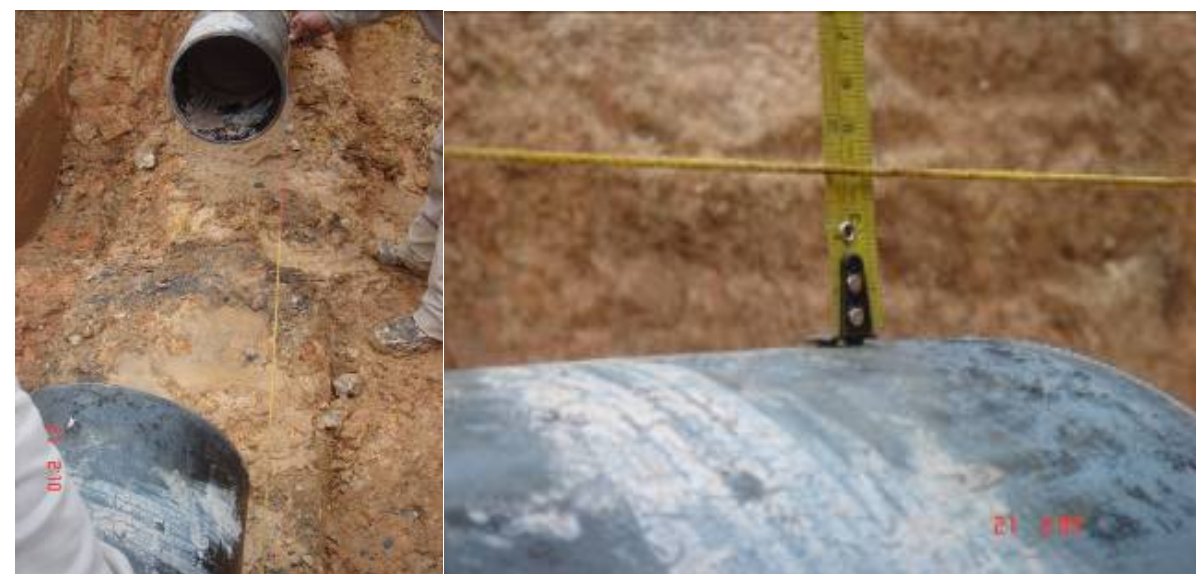

Figure 6. Pipeline cut at the $3+300$ kilometer. 


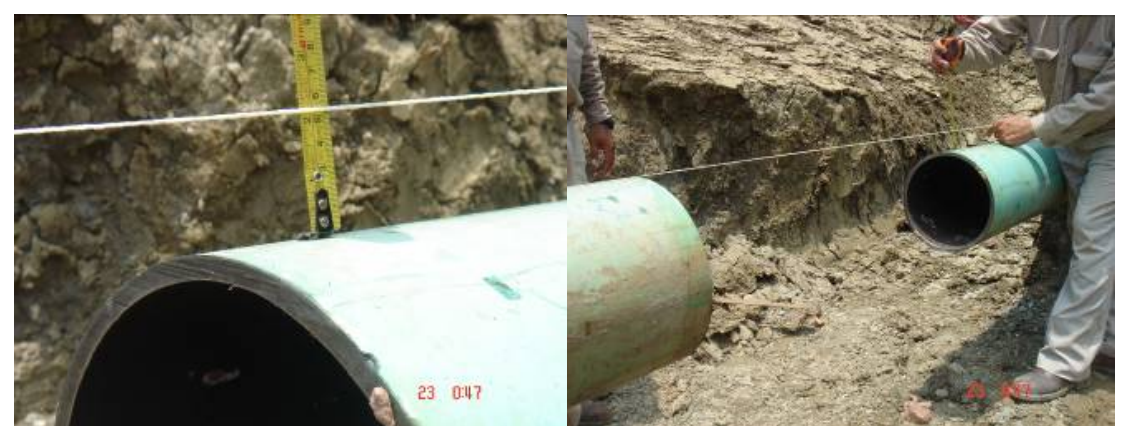

Figure 7. Pipeline cut at the $8+025$ kilometer.

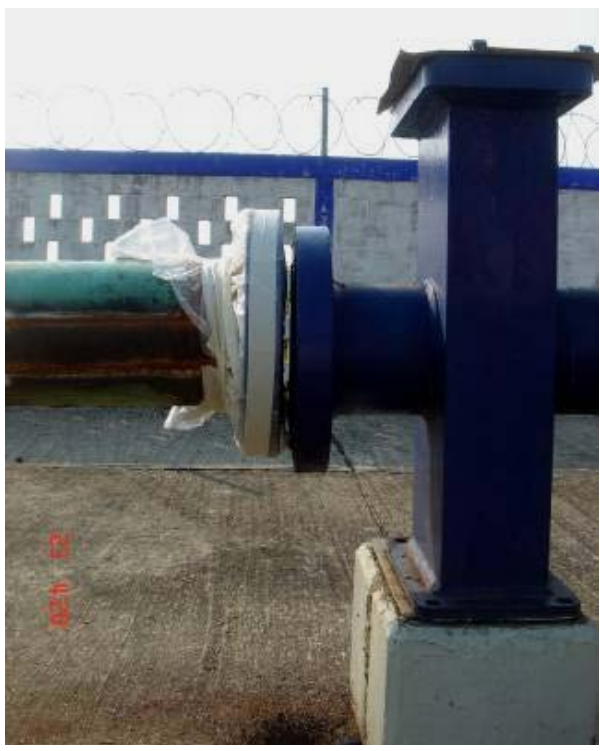

Figure 8. Pipeline vertical displacement at the sectional valve.

\subsection{Pipeline Flexibility}

By considering the pipeline loads and operative conditions, along with the topographic profile of the terrain reported by the GPS of the last ILI inspection [23], a pipeline flexibility analysis was performed to identify the zones or sites with higher stress levels and/or displacement probability. The results showed (Figure 9 and Figure 10) that the pipeline is submitted to stress conditions that don't surpasses $35 \%$ of the allowed limits established by ASME B31.4 2009 [24]. There are displacement points and relatively high stress levels (peaks) in the zones where failures occurred in the pipeline. The highest displacements and stress levels were located at two sectional valves $(15+161$ and $30+034$ kilometers). In addition, there is a region with stress fluctuations that are in accordance with the highest occurrence of pipeline failures.

\subsection{Direct Inspection}

By considering the high stress and displacement levels, strain variations from the flexibility analysis, leaks record and stress induced during pipeline construction, 13 sites 
were selected to carry out a field direct evaluation, using ultrasonic technology with industrial phase arrangement for the detection of possible cracks, along with other non-destructive field techniques [25].

The direct evaluation results showed the presence of cracks at the $3+371$ and $15+$ 161 kilometers (Table 4 and Table 5) and microstructures with fragile aspect and/or high hardness at different sites.

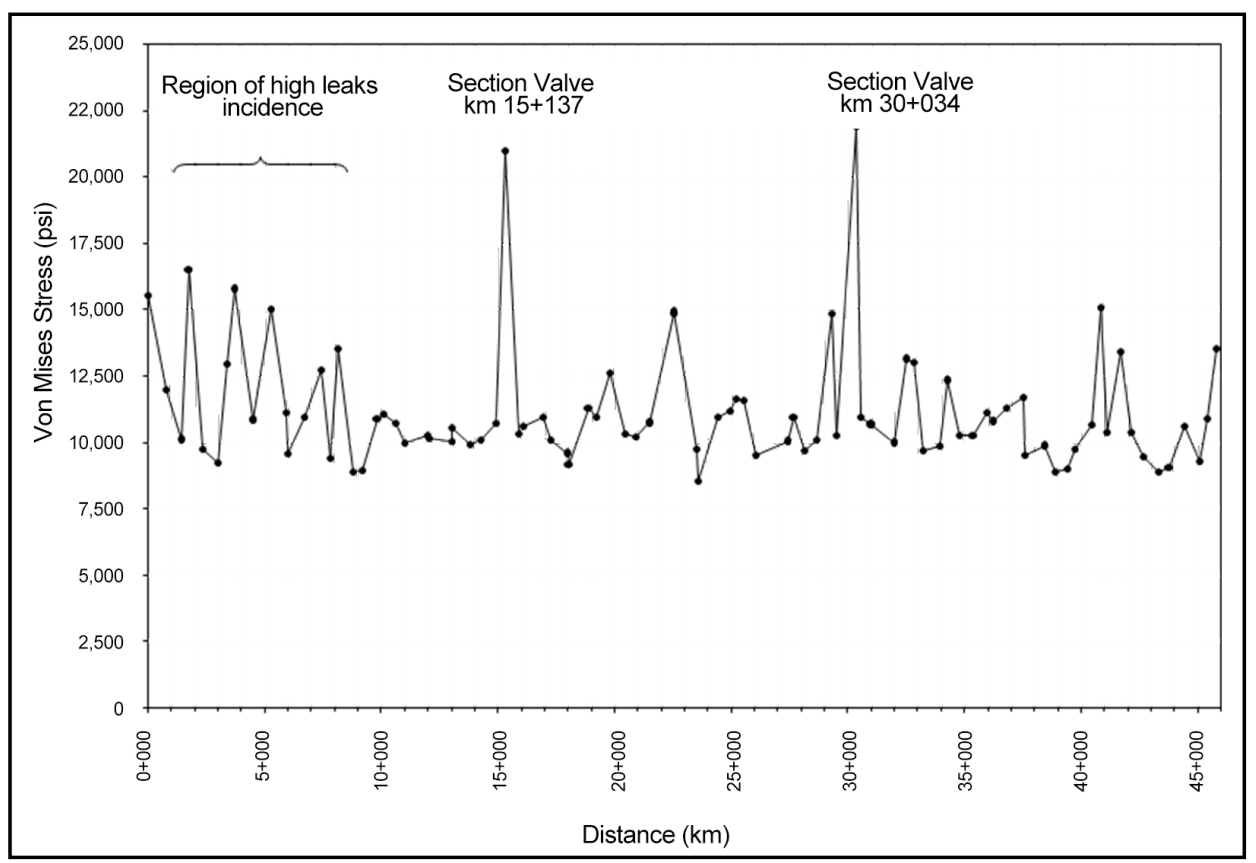

Figure 9. Pipeline stress profile.

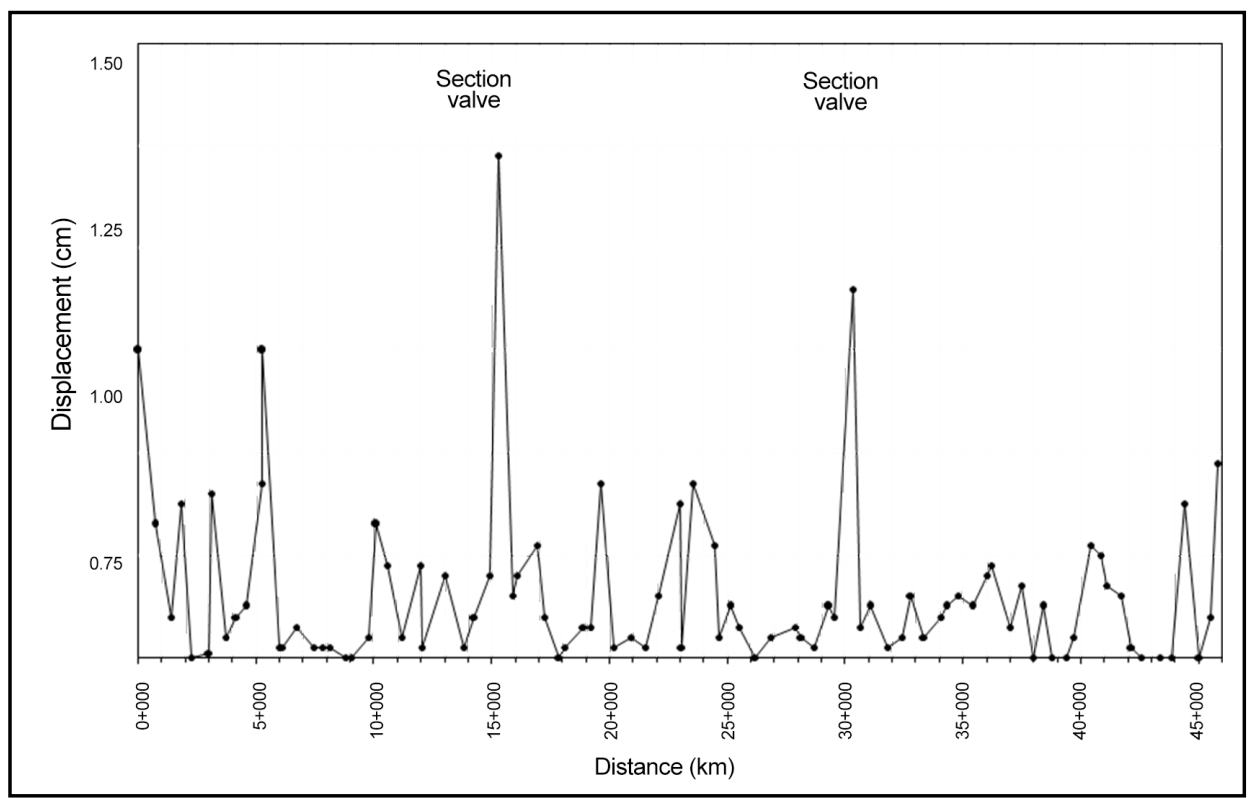

Figure 10. Pipeline displacement profile. 


\subsection{Evaluation of the Ammonia Pipeline}

The probability of cracking throughout the pipeline was established by analyzing and putting together the evidence of the pipeline historical records and those obtained from recent works and field and/or laboratory studies; considering, in general, eight factors or aspects and relative scores (Table 6).

Table 4. Results of the direct evaluation at the $3+371$ kilometer.

$\begin{array}{cl}\text { Type } & \text { Crack confined inside the pipe body. } \\ \text { Location } & 12 \text { technical hours from the pipe, at } 40 \mathrm{~mm} \text { of field weld. } \\ \text { Dimensions } & 11.43 \mathrm{~mm} \text { of circumferential length and } 0.077 \text { " of radial length, Figure } 11 . \\ \text { Crack mechanics: Crack located at the "no failure zone". The failure stress is } \\ 47 \% \text { of the applied stress. } \\ \text { Revaluation } & \begin{array}{l}\text { Repair with a type B sleeve, designed to contain the pipeline operation pressure } \\ \text { in the case of a leak or the possible replacement of the pipe. }\end{array} \\ \text { Performed action } & \text { Pipe replacement. }\end{array}$

Table 5. Results of the direct evaluation at the $15+161$ kilometer.

\begin{tabular}{cl}
\hline Type & $\begin{array}{l}\text { Crack confined inside the pipe body. } \\
\text { Location }\end{array}$ \\
$\begin{array}{l}12 \text { technical hours from the pipe, at } 16 \mathrm{~mm} \text { of field weldand at } 0.220 \text { " of the } \\
\text { external pipe surface. } \\
\text { Dimensions }\end{array}$ & $\begin{array}{l}23.36 \mathrm{~mm} \text { of circumferential length and } 0.143 \text { " of radial length, Figure } 12 . \\
\text { Crack mechanics: Crack located at the "no failure zone". The failure stress is } \\
74 \% \text { of the applied stress. } \\
\text { Evaluation }\end{array}$ \\
Recomendation & Pipe replacement. \\
Performed action & Pipe replacement.
\end{tabular}

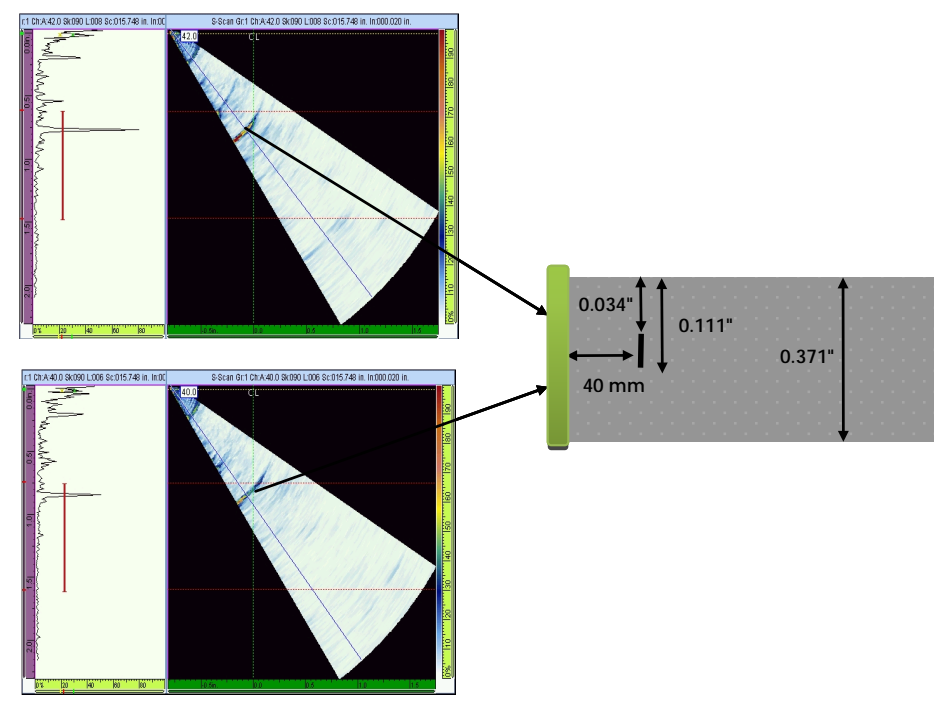

Figure 11. Dimensioning and location of a crack at the $3+371 \mathrm{~km}$. 

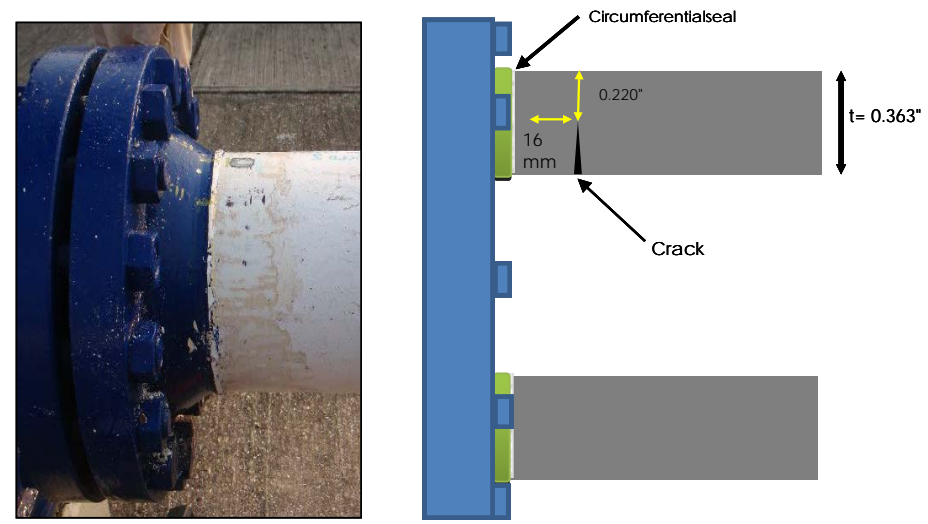

Figure 12. Location of the crack at the $15+161 \mathrm{~km}$.

Table 6. Factors / aspects for cracking probability analysis.

\begin{tabular}{|c|c|c|c|c|}
\hline No. & Factor/Aspect & Reference & Cracking Probability & Score \\
\hline 1 & Leaks & Historical records & Very high failure probability & 100 \\
\hline 2 & $\begin{array}{l}\text { High hardness in the } \\
\text { base material } \\
\text { (susceptible material) }\end{array}$ & $\begin{array}{l}\text { Metallographic analyses } \\
\text { laboratory/field }\end{array}$ & $\begin{array}{l}\text { High failure probability if } \\
\text { stress levels are increased }\end{array}$ & 80 \\
\hline 3 & $\begin{array}{l}\text { By force withdrawn/ } \\
\text { installed sections } \\
\text { (high stress levels) }\end{array}$ & Field works & High failure probability & 80 \\
\hline 4 & $\begin{array}{c}\text { Linearity recovery of } \\
\text { withdrawn pipe sections } \\
\text { (high stress levels) }\end{array}$ & Field works & Very high failure probability & 100 \\
\hline 5 & Identified cracks & $\begin{array}{c}\text { Metallographic analyses } \\
\text { laboratory/field }\end{array}$ & High failure probability & 100 \\
\hline 6 & High stress level sites & Flexibility analysis & $\begin{array}{c}\text { Intermediate failure } \\
\text { probability if combined } \\
\text { with susceptible materials }\end{array}$ & 50 \\
\hline 7 & $\begin{array}{l}\text { Sites with high } \\
\text { displacement }\end{array}$ & Flexibility analysis & $\begin{array}{c}\text { Intermediate failure } \\
\text { probability if combined } \\
\text { with susceptible materials }\end{array}$ & 50 \\
\hline 8 & $\begin{array}{l}\text { Sites with varying } \\
\text { stress level }\end{array}$ & Flexibility analysis & $\begin{array}{l}\text { High failure } \\
\text { probability if combined } \\
\text { with susceptible materials }\end{array}$ & 80 \\
\hline
\end{tabular}

In order to establish the cracking probability in the pipeline, intervals indicated in Table 7 were considered, which are based on the addition of the scores of the considered factors or aspects.

The results show that approximately $50 \%$ of the pipeline length has high or very high probability of cracking failure (from $0+000$ to $22+036$ kilometers); and that the most critical segments are located from $0+000$ to $7+900 \mathrm{Km}$ and from $15+161$ to $15+291$ km (Table 8). 
Table 7. Cracking probability score intervales.

\begin{tabular}{cc}
\hline Cracking probability & Score intervals \\
\hline Very high & $\geq 400$ \\
High & 200 to 399 \\
Intermediate & $<200$ \\
\hline
\end{tabular}

Table 8. Cracking probability.

\begin{tabular}{cccccccccc}
\hline \multirow{2}{*}{ Length (km) } & \multicolumn{8}{c}{ Factors } & Cracking probability \\
\cline { 2 - 7 } & 1 & 2 & 3 & 4 & 5 & 6 & 7 & 8 & Very high \\
\hline $0+000-7+900$ & $\checkmark$ & $\checkmark$ & $\checkmark$ & $\checkmark$ & $\checkmark$ & $\checkmark$ & $\checkmark$ & $\checkmark$ & High \\
$8+070-10+105$ & - & - & $\checkmark$ & - & - & $\checkmark$ & $\checkmark$ & $\checkmark$ & Very high \\
$15+161-15+291$ & $\checkmark$ & $\checkmark$ & - & - & $\checkmark$ & $\checkmark$ & $\checkmark$ & - & High \\
$16+912-22+036$ & - & - & $\checkmark$ & $\checkmark$ & - & $\checkmark$ & $\checkmark$ & - & Intermediate \\
$22+515-29+319$ & - & - & - & - & - & $\checkmark$ & $\checkmark$ & - & Intermediate \\
$30+034-30+349$ & - & - & - & - & - & $\checkmark$ & $\checkmark$ & - & Intermediate \\
$32+522-45+494$ & - & - & - & - & - & $\checkmark$ & $\checkmark$ & - & \\
\hline
\end{tabular}

As a considerable pipeline length shows high probability of cracking failure (22 kilometers), the first option would be to carry out field actions to eliminate and/or release the stress to which the pipeline is submitted.

Already tested releasing stress for this type of situations are excavations of several kilometers to uncover the pipeline in order to it be elastically displaced (cold "bouncing" or "spring back"), carrying out specific cuts and "no-forced" joints with transition reels.

From the operative, logistic and financial standpoints, the already mentioned option is considered as unviable and it is only recommendable to perform the necessary actions to construct a new pipeline with suitable fabrication, construction and installation specifications aimed at preventing the SCC phenomenon from happening.

\section{Conclusions}

The field and laboratory studies confirmed that the origin of the leaks at the ammonia pipeline studied in the present work obeyed to a Stress Cracking Corrosion (SCC) mechanism of brittle type, which was the result of the interaction among a fragile material, an intermediate corrosive medium and high residual stress levels originated from the pipeline construction.

The steel used to produce the pipes is more susceptible than normal to stress cracking due to the fact that it exhibits high hardness, high stress resistance and a brittle microstructure.

The analyses of failure probability, considering the pipeline historical documental records and the recent works, along with field and/or laboratory studies, indicate that approximately $50 \%$ of the pipeline length shows high or very high probability of cracking failure. 
From the operative, logistic and financial points of view, it is not feasible to release the stress of approximately $22 \mathrm{~km}$ of pipeline and only the construction of a new pipeline with suitable fabrication, construction and installation specifications aimed at preventing the SCC phenomenon from happening is viable.

The SCC mechanism is well identified for these types of systems and its development is expected. Therefore, it is necessary to consider the following recommendations, in order to decrease the SCC probability:

- To consider studies and kinematic registers of the ground where the pipeline is lying, in order to determine the mass movements or batter.

- To minimize the residual stresses originated in the base metal during construction, considering also a heat treatment for stresses relief when welding is applied.

- To monitor, through nondestructive techniques and tests, the occurrence of failure susceptible zones, considering factors such as hardness increase, metal strains and stresses rise, along with the type of fluid transported by the pipeline.

- To identify critical areas such as welding, pipeline deviations, hits or pipeline failures during lying, in order to follow their behavior against conditions to which the pipeline is subjected.

\section{References}

[1] Popov, B.N. (2015) Stress Corrosion Cracking. In: Corrosion Engineering, Principles and Solved Problems, Capítulo 9, 365-450.

http://dx.doi.org/10.1016/b978-0-444-62722-3.00009-4

[2] Cheng, Y.F. (2013) Stress Corrosion Cracking of Pipelines. John Wiley \& Sons, 288 p.

[3] Heidersbach, R. (2011) Metallurgy and Corrosion Control in Oil and Gas Production. 296 p. http://dx.doi.org/10.1002/9780470925782

[4] Jones, R.H. (1992) Stress-Corrosion Cracking. ASM International, 445 p.

[5] Mahajanam Sudhakar, P.V., Mcintyre Dale, R. and Hovey Lawrence, K. (2009) Residual Stress Control to Prevent Environment Cracking of Stainless Steels. Materials Performance, 48, 60-64.

[6] Carcea, A.G. and Newman, R.C. (2010) Mechanistic Studies of Stress Corrosion Cracking of Carbon Steel in Alcoholic Solutions. 218th ECS Meeting, The Electrochemical Society, 1245 .

[7] Antunes, P.D., Correa, E.O., Barbosa, R.P., Silva, E.M., Padilha, A.F. and Guimaraes, P.M. (2013) Effect of Weld Metal Chemistry on Stress Corrosion Cracking Behavior of AISI 444 Ferritic Stainless Steel Weldments in Boiling Chloride Solution. Materials and Corrosion, 64, 415-421. http://dx.doi.org/10.1002/maco.201106186

[8] Lu, B.T., Chen, Z.K., Luo, J.L., Patchett, B.M. and Xu, Z.H. (2005) Pitting and Stress Corrosion Cracking Behavior in Welded Austenitic Stainless Steel. Electrochimica Acta, 50, 13911403. http://dx.doi.org/10.1016/j.electacta.2004.08.036

[9] Balraj, V. and Paul, R. (2009) Evaluation of Weld Root Corrosion of Type 316L Stainless Steel. Materials Performance, 48, 80-82.

[10] Ramesh, S. (2009) Ethanol Corrosion in Pipelines. Materials Performance, 48, 53-55.

[11] Janikowski Daniel, S. (2008) Selecting Tubing Materials for Power Generation Heat Exchangers. Materials Performance, 47, 58-63. 
[12] Linton, V.M. and Laycock, N.J. (2008) Stress Corrosion Cracking of a Vinyl Chloride Stripper Vessel. Materials Performance, 47, 74-79.

[13] Loginow, A.W. (1989) Stress Corrosion Cracking of Steel in Liquefied Ammonia ServiceA Recapitulation. National Board Classic Series, National Board Bulletin.

[14] Cottis, R.A. (2000) Stress Corrosion Cracking-Guides to Good Practice in Corrosion Control. The National Physical Laboratory, 1-16. www.npl.co.uk

[15] Guidance for Inspection of and Leak Detection in Liquid Ammonia Pipelines. 2008 Edition, Issue 2013, Fertilizer Europe.

[16] ASTM E3-11. Standard Guide for Preparation of Metallographic Specimens.

[17] ASTM E340-15. Standard Practice for Macroetching Metals and Alloys.

[18] ASTM E407-07 (2015) Standard Practice for Microetching Metals and Alloys.

[19] ASTM E112-13. Standard Test Methods for Determining Average Grain Size.

[20] ASTM E8/E8M-15a. Standard Test Methods for Tension Testing of Metallic Materials.

[21] ASTM E10-15a. Standard Test Method for Brinell Hardness of Metallic Materials.

[22] ASTM E140-12b. Standard Hardness Conversion Tables for Metals Relationship among Brinell Hardness, Vickers Hardness, Rockwell Hardness, Superficial Hardness, Noop Hardness, Scleroscope Hardness, and Leeb Hardness.

[23] NACE SP0102-2010. Standard Practice, In-Line Inspection of Pipelines.

[24] ASME B31.4-2009. Pipeline Transportation Systems for Liquid Hydrocarbons and Other Liquids.

[25] ASTM E213-14. Standard Practice for Ultrasonic Testing of Metal Pipe and Tubing.

Submit or recommend next manuscript to SCIRP and we will provide best service for you:

Accepting pre-submission inquiries through Email, Facebook, LinkedIn, Twitter, etc.

A wide selection of journals (inclusive of 9 subjects, more than 200 journals)

Providing 24-hour high-quality service

User-friendly online submission system

Fair and swift peer-review system

Efficient typesetting and proofreading procedure

Display of the result of downloads and visits, as well as the number of cited articles

Maximum dissemination of your research work

Submit your manuscript at: http://papersubmission.scirp.org/

Or contact msa@scirp.org 